\title{
PIGI ZOIS: Pioneering with credibility
}

\section{Vasilios Perifanis, ${ }^{1}$ Ourania Pantelidou, ${ }^{2}$ Nousiou Charikleia, ${ }^{3}$ Miranda Athanassiou-Metaxa, ${ }^{4}$ Electra Kolokytha-Grammatikopoulou ${ }^{5}$}

\author{
${ }^{1}$ Assistant Professor of Hematology, School of Medicine, Faculty of Health Sciences, Aristotle \\ University, Secretary General of PIGI ZOIS; ${ }^{2}$ Professor of Endodontology, School of Dentistry, \\ Faculty of Health Sciences, Aristotle University, Vice-president of PIGI ZOIS; ${ }^{3}$ Accountant, \\ Treasurer of PIGI ZOIS; ${ }^{4}$ Professor Emeritus of Pediatrics, Honorary President of PIGI ZOIS, \\ ${ }^{5}$ Dentist, President of PIGI ZOIS, Thessaloniki, Greece
}

\begin{abstract}
Annual transfusion requirements in Greece exceed 600000 blood units and nearly $20 \%$ of them are used for the transfusion of 3.000 patients with Thalassemia. Thalassemia patients need to be transfused properly at the right time and with safe, fresh blood. PIGI ZOIS is a nonprofit organization that tries to improve the lives of patients through providing proper voluntary blood units to patients and enhancing the Voluntary Blood Donation policy, in Thessaloniki area, which has 350 patients. The mission of PIGI ZOIS is to organize and manage almost 7.000 volunteers to donate their blood for the thalassemic patients. This is achieved by using a phone call reminder, so that the blood volunteer will donate his/her blood to a compatible young patient. All matches are done by a specialized computer program. PIGI ZOIS has donated 90.000 blood units over a period of twenty years. PIGI ZOIS also aims to raise awareness of Thalassemia through an educational program with children in primary schools, with the ultimate goal of encouraging the children to become donors when they reach adulthood. PIGI ZOIS also runs informative campaigns to the public about disease prevention and the general promotion of voluntary blood donation.
\end{abstract}

\section{Introduction}

The world is making slow progress towards the goal of $100 \%$ unpaid, voluntary blood donation, falling short of ensuring the safety and the sustainability of blood supplies. Transfusion requirements in Greece exceed 600000 blood units per year. Nearly $20 \%$ of them are used for the transfusion of 3000 patients with Thalassemia. The high prevalence of the Thalassemia gene in the Greek population along with the economic burden associated with the care of the disease, make Thalassemia a significant public health concern. Voluntary blood donation accounts for about $50 \%$ of the blood collected annually. Thalassemia patients

Correspondence: Vasilios Perifanis, Assistant Professor of Hematology, School of Medicine, Faculty of Health Sciences, Aristotle University, Secretary General of PIGI ZOIS, Greece.

This work is licensed under a Creative Commons Attribution 4.0 License (by-nc 4.0).

(C) Copyright V. Perifanis et al., 2018

Licensee PAGEPress, Italy

Thalassemia Reports 2018; 8:7492

doi:10.4081/thal.2018.7492 need transfusions to be undertaken in a timely and proper fashion using safe, fresh blood.

The aim of this presentation is to show how an association of voluntary blood donors managed to successfully face this challenge.

\section{Presentation}

A Board of coordination of Transfusion Policy was established 30 years ago in Thessaloniki area, in order to give the 350 thalassaemia patients the best available transfusion therapy. Ten years later a NGO (Non-governmental organization) PIGI ZOIS ("The Spring of Life" in Greek) was founded to continue and strengthen this policy (Figure 1). PIGI ZOIS is a nonprofit organization that tries to improve the lives of patients through providing proper voluntary blood units to patients and enhancing Voluntary Blood Donation policy. Every patient has at least 10 or more voluntary blood donors fully matched for compatible blood (and not only for $\mathrm{ABO}$ grouping) that are called by phone (or by sms) to donate every time the patient is scheduled for a transfusion. All donors are registered electronically with their personal information, their blood group and the time of their last donation. All patients' blood groups are also registered as well as their expected transfusion day and the matches are done by the computer, with the help of a specialized software application. The mission of PIGI ZOIS is to organize and manage almost 7,000 volunteers to donate their blood for the patients with Thalassemia. This happens after a phone call reminder, so that the blood volunteer will give his/her blood to a fully compatible young patient. The donor is asked to do so in a

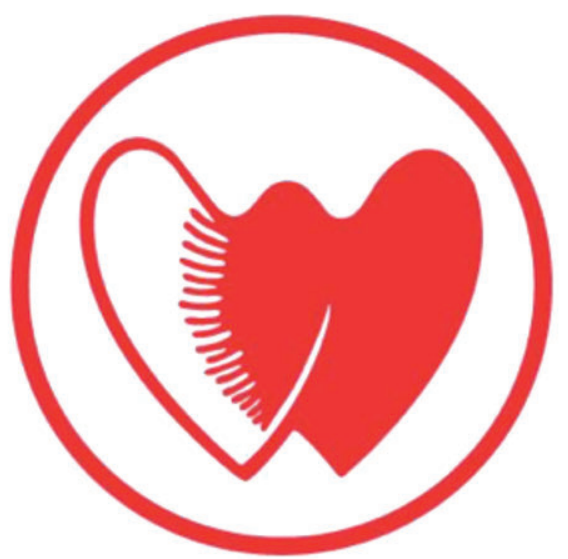

Figure 1. Logo of PIGI ZOIS. 


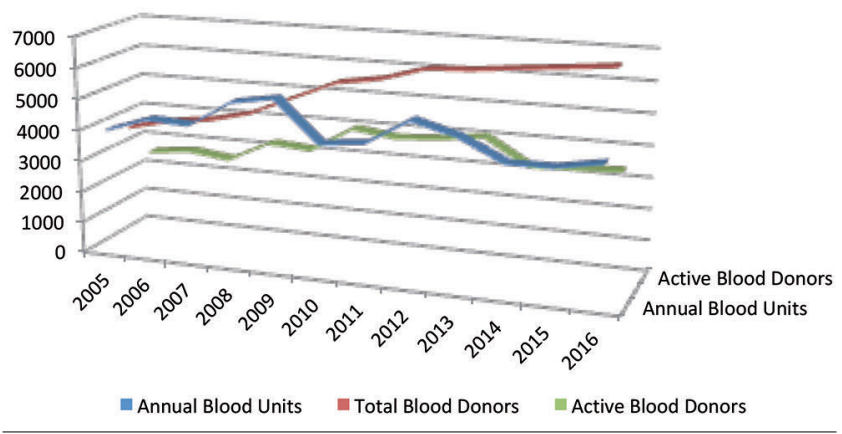

Figure 2. Total registered blood donors, active blood donors (June 2017) and Annual Blood units donated for thalassemia patients during the last twelve years (2005-2016).

period of a week prior to the transfusion of the patient. Nowadays, after 20 years of hard work, PIGI ZOIS has records of 6,929 voluntary blood donors $(3,349$ still active $)$ that is constantly renewed, who donate regularly and covers about one third of annual blood requirements in the Thessaloniki area. Median annual blood donations from PIGI ZOIS reach 4,502 units (range 3973-5425). Finally, everybody gains: the volunteer gives blood 2 or 3 times per year and the patient doesn't worry about their next scheduled transfusion. All of this was made possible with the impeccable cooperation of the Local Thalassemia Association of the patients and the city's Blood Banks. Every year phone calls to donors reach approximately 10,000. Registered blood donors numbered 2,500 at the beginning of the century, 5,723 on 2010 and 6,820 on 2016 (Figure 2). Every four years all donors reaching more than forty donations are "rewarded" with a commemorative gift in a special organized public event.

Another objective of PIGI ZOIS is to inform and encourage the public about making Blood donations, as well as recruiting new blood donors to replace those that cannot donate anymore for health reasons. Of particular interest is the campaign to inform and excite children in primary schools through a "learn and play" activity based on a cartoon-program (originally made in France, 15 years ago) displaying everything about blood and its elements. This is a school-based information program on blood and donation, built around the cartoon "Journey to the Heart of Life". The purpose of the "Globulyss" (Greek word: "Hemospheria") program designed by ADOSEN and the association "Au coeur de la vie", in partnership with the French Blood Establishment, is to present in simple words the blood components and the donation procedure to children through playful and interactive media. PIGI ZOIS has translated this program (CDs and books- one for the teacher and one for the pupil) and adapted it with Greek data. We now have the permission of the Ministry of Education and we have succeeded in incorporating the project into our schools for six consecutive years with astonishing results from our youngsters. The project is scheduled to inspire altruistic behavior in the young population, thereby encouraging them to become blood donors when they reach adulthood. At the end of the academic year every participating school presents small plays, songs, paintings or games inspired by the program, at a festival that promotes volunteering.

PIGI ZOIS participates every year in the celebration of World Thalassemia Day by an informative campaign in the streets of Thessaloniki, in order to make people aware of the disease and to recruit new blood donors. This is achieved by handing out brochures about the disease and emphasizing the benefits of the National Prevention Programme, originally initiated in 1974 and already successful in reducing affected births. However, in recent years new cases have been recorded from the refugee population that has reached Greece from areas of high Thalassemia prevalence.

PIGI ZOIS is usually funded by donations and by the annual members' fees and is run primarily by volunteers. Other sources of finance include two annual bazaars (every Christmas and Easter) and cultural events, like concerts. The organization has received local and national awards for its commitment to the purpose of augmenting voluntary blood donation in Greece.

\section{Conclusions}

PIGI ZOIS ' pioneering action, has become a reality thanks to the support of enthusiastic fellow Greek volunteers and shows the way to achieve safe and sustainable blood supplies without neglecting the credibility of transfusions for Thalassaemia patients. 